\title{
CHANGES OF X-RAY PHOTOELECTRON SPECTRA BY ION SPUTTERING
}

\author{
*Satoshi Hashimoto, ${ }^{*}$ Kichinosuke Hirokawa, ${ }^{*}$ YYasuo Fukuda, ${ }^{*}$ Keni-chi Suzuki, \\ ${ }^{*}$ Toshiko Suzuki, ${ }^{*} 6$ Noriaki Usuki, ${ }^{* 7}$ Norio Gennai, ${ }^{*} 8$ Sizuo Yoshida, ${ }^{*} 9$ Mitsuru Koda, \\ ${ }^{*} 10$ Hiroshi Sezaki, ${ }^{*} 1$ Hiroshi Horie, ${ }^{*} 12$ Akihiro Tanaka and ${ }^{*} 13$ Takashi Ohtsubo \\ *Steel Research Center. NKK Corp., ${ }^{* 2}$ Tohoku University, ${ }^{3}$ Shizuoka University, ${ }^{* 4}$ Nippon \\ Steel Corp., ${ }^{* 5}$ Kawasaki Steel Corp., ${ }^{* 6}$ Sumitomo Metal Industries, Ltd., ${ }^{*}{ }^{K}$ KOBELCO \\ Research Institute, Inc., ${ }^{*} 8$ Daido Steel Co., Ltd., ${ }^{*}{ }^{2}$ Nisshin Steel Co., Ltd., ${ }^{*} 10$ Hitachi Metals \\ Ltd., ${ }^{*} 11$ Kyushu Electronic Metal Co., Ltd., ${ }^{*} 12$ ULVAC-PHI Inc. and ${ }^{*}{ }^{13}$ The Japan Iron \& \\ Steel Federation \\ *1-1 Minamiwatarida, Kawasaki, Kanagawa 210, Japan
}

\begin{abstract}
Round-robin experiments have revealed that the O1s XPS line gives a better correction of the binding energy shift by the charge up than the C1s XPS line does. Moreover, a oxide can be unchanged or damaged or reduced by ion sputtering and the change can be predicted by the ionisity and the free formation enthalpy.
\end{abstract}

Key word x-ray photoelectron spectroscopy (XPS), binding energy, charge up, ion sputtering, oxide

\section{INTRODUCTION}

It has been reported that the correction using $\mathrm{C} 1 \mathrm{~s}$, which originates from the contamination of carbon, does not always give a correct binding energy [1]. Chemical states of several compounds are altered by ion bombardment used for depth profiling in XPS (X-ray Photoelectron Spectroscopy) [2]. Round-robin experiments have been performed in order to establish the correction of the binding energy of XPS spectra for oxides by charging resulting from radiation of $\mathrm{x}$-rays or $\mathrm{Ar}$ ion sputtering and to determine the criteria for the change of chemical state by Ar ion sputtering.

\section{EXPERMENTAL}

The XPS spectrometers used in the round-robin measurements by the seven laboratories are shown in TABLE 1. Plates of $\mathrm{Al}_{2} \mathrm{O}_{3}, \mathrm{SiO}_{2}, \mathrm{MgO}$ and $\mathrm{TiO}_{2}$ and powder of $\mathrm{NiO}$ were used as specimens. $\mathrm{Al} 2 \mathrm{p}(\mathrm{Si} 2 \mathrm{p}, \mathrm{Mg} 1 \mathrm{~s}, \mathrm{Ti} 2 \mathrm{p}$ and $\mathrm{Ni} 2 \mathrm{p}), \mathrm{C} 1 \mathrm{~s}$ and $\mathrm{O} 1 \mathrm{~s}$ spectra for $\mathrm{Al}_{2} \mathrm{O}_{3}\left(\mathrm{SiO}_{2}, \mathrm{MgO}\right.$, $\mathrm{TiO}_{2}$ and $\mathrm{NiO}$ ) were measured while $\mathrm{Ar}$ ion sputtering were performed until the binding energy and intensity of every line became stable.

*Present address; 1 Kokan-cho, Fukuyama, Hiroshima 721, Japan 
TABLE 1 XPS spectrometers used for the round-robin experments

\begin{tabular}{c|c|c|c}
\hline Lab. & Model & Analyzer & Source \\
\hline \hline B & VG-ESCA3 Mark II & Hemispherical & $\mathrm{Al} \mathrm{K \alpha}$ \\
\hline C & Kratos Model ES-300 & Hemispherical & $\mathrm{Al} \mathrm{K \alpha}$ \\
\hline D & VG-ESCA Lab 5 & Hemispherical & $\mathrm{Al} \mathrm{K \alpha}$ \\
\hline E & VG-ESCA3 Mark II & Hemispherical & $\mathrm{Al} \mathrm{K \alpha}$ \\
\hline F & PHI-550E & CMA & $\mathrm{Mg} \mathrm{K \alpha}$ \\
\hline I & PHI-5300 & Hemispherical & $\mathrm{Al} \mathrm{K \alpha}$ \\
\hline K & PHI-5400MC & Hemispherical & $\mathrm{Al} \mathrm{K \alpha}$ \\
\hline
\end{tabular}

\section{RESULTS AND DISCUSSION}

\section{Correction of binding energy Binding} energy shift of the Al2p ( $\mathrm{Si} 2 \mathrm{p}$ or $\mathrm{Mg} 1 \mathrm{~s}$ ) line by charge up which is caused by radiation of $\mathrm{x}$-ray and ion sputtering shifts to a high binding energy in $\mathrm{Al}_{2} \mathrm{O}_{3}\left(\mathrm{SiO}_{2}\right.$ or $\left.\mathrm{MgO}\right)$. The amount of shift is different among the laboratories and samples; it is clear that the differences between the $\mathrm{O} 1 \mathrm{~s}$ and $\mathrm{Al} 2 \mathrm{p}$ lines are much smaller than those between the $\mathrm{C} 1 \mathrm{~s}$ and Al2p lines. Fig. 2 shows the binding energy differences between $\mathrm{O} 1 \mathrm{~s}$ and $\mathrm{Al} 2 \mathrm{p}$ lines of $\mathrm{Al}_{2} \mathrm{O}_{3}$ which are measured at the seven laboratories. The scatter of the binding energy differences between the $01 \mathrm{~s}$ and Al2p lines is less than $1 \mathrm{eV}$ among the laboratories. The scatter of the binding energy differences between the $\mathrm{O} 1 \mathrm{~s}$ and $\mathrm{Si} 2 \mathrm{p}(\mathrm{Mg} 1 \mathrm{~s})$ lines of $\mathrm{SiO}_{2}(\mathrm{MgO})$ was also as small as those between the $\mathrm{C} 1 \mathrm{~s}$ and $\mathrm{Si} 2 \mathrm{p}$ (Mg1s) lines. The round-robin measurements reveal that the correction using the binding energy of the $\mathrm{O} 1 \mathrm{~s}$ line give a better correction for the binding energy shift of $\mathrm{Al}_{2} \mathrm{O}_{3}\left(\mathrm{SiO}_{2}\right.$ or $\left.\mathrm{MgO}\right)$ than that using the binding energy of the $\mathrm{C} 1 \mathrm{~s}$ line which is commonly used.

Change of the chemical state by ion sputtering Fig. 3 shows the change of Ti2p XPS spectra of $\mathrm{TiO}_{2}$ as a function of $\mathrm{Ar}$ ion sputtering time. After Ar ion sputtering, components of $\mathrm{Ti}^{3+}$ and $\mathrm{Ti}^{2+}$ appear besides that of $\mathrm{Ti}^{4+}$ in the Ti2p line. A component of $\mathrm{Ni}^{0}$ appeared besides that of $\mathrm{Ni}^{2}+$ in the $\mathrm{Ni} 2 \mathrm{p}$ line of $\mathrm{NiO}$. The additional components of $\mathrm{TiO}_{2}$ and $\mathrm{NiO}$ by $\mathrm{Ar}$ ion sputtering is due to the reduction of the oxides, which agrees with the previous results [4][5].

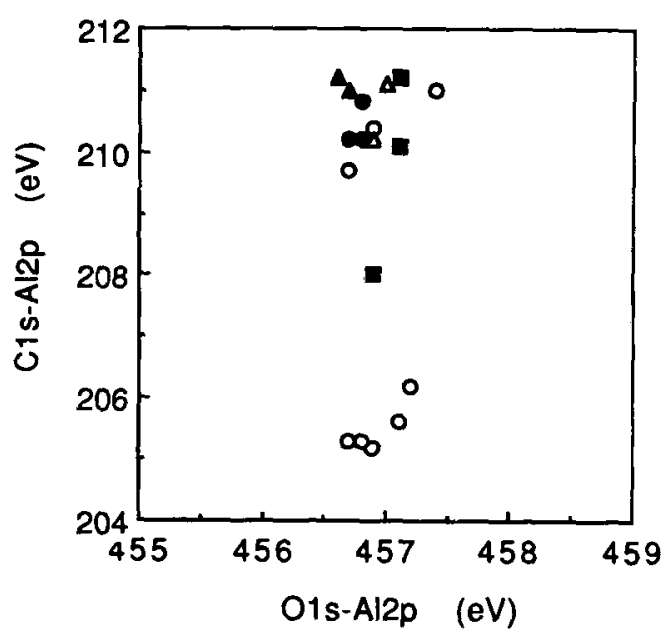

Fig. 1 Relationship between binding energy difference between $\mathrm{C} 1 \mathrm{~s}$ and $\mathrm{Al} 2 \mathrm{p}$ lines of $\mathrm{Al}_{2} \mathrm{O}_{3}$ plate and that between for $\mathrm{O} 1 \mathrm{~s}$ and Al2p lines. (Lab. : O; C, $\bullet ; \mathrm{D}, \Delta ; \mathrm{E}, \boldsymbol{\Delta} ; \mathrm{F}, \boldsymbol{\square} ; \mathrm{I}$ )

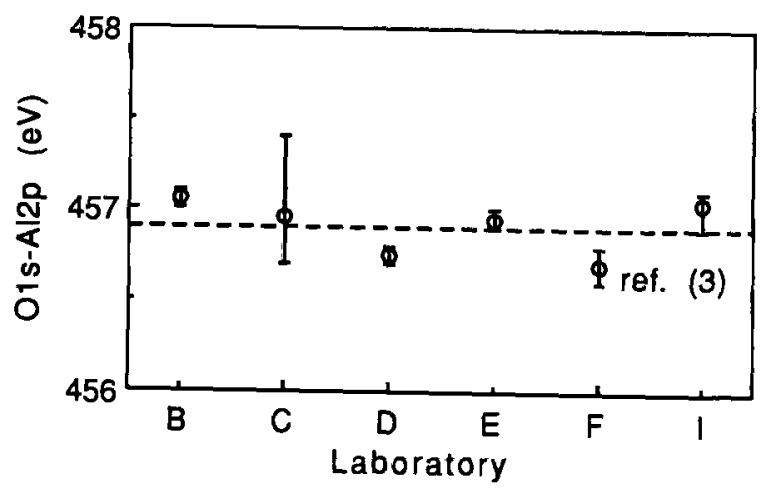

Fig. 2 Binding energy difference between $\mathrm{O} 1 \mathrm{~s}$ and $\mathrm{Al} 2 \mathrm{p}$ lines of $\mathrm{Al}_{2} \mathrm{O}_{3}$ plate at each laboratory.

Fig. 4 shows FWHM (Full Width Half Maximum) of the $\mathrm{Al} 2 \mathrm{p}$ line of $\mathrm{Al}_{2} \mathrm{O}_{3}, \mathrm{Si} 2 \mathrm{p}$ line of $\mathrm{SiO}_{2}$ and $\mathrm{Mg} 1 \mathrm{~s}$ line of $\mathrm{MgO}$ before and after Ar ion sputtering. The FWHM of the Al2p line and the Si2p line increase by Ar ion sputtering, although new components are not observed in 
$\mathrm{Al}_{2} \mathrm{O}_{3}$ and $\mathrm{SiO}_{2}$. The increase of FWHM results from the damage induced at the surface by ion sputtering [6]. On the other hand, no changes are seen in XPS spectra of $\mathrm{MgO}$ by ion sputtering.

The change of the chemical state for the oxides by ion sputtering is classified to three categories. The chemical state is not changed in the oxides of the first category as exemplified by $\mathrm{MgO}$, the damage is induced in the oxides of the second category as $\mathrm{Al}_{2} \mathrm{O}_{3}$ and $\mathrm{SiO}_{2}$ and the oxides in the third category such as $\mathrm{TiO}_{2}$ and $\mathrm{NiO}$ are reduced. Kelly et al. proposed a criteria for the change of the chemical state by ion sputtering that the oxides are reduced when the free formation enthalpy of an oxide is smaller than that of the thermally reduced oxide [7]. Moreover, a tendency is seen that the oxides having the ionic character such as $\mathrm{MgO}$ are not changed by ion sputtering.

Comparing the published data for the oxides [2] with our data, the changes of the chemical state for the oxides by ion sputtering can be classified by the free formation enthalpy and the ionicity.

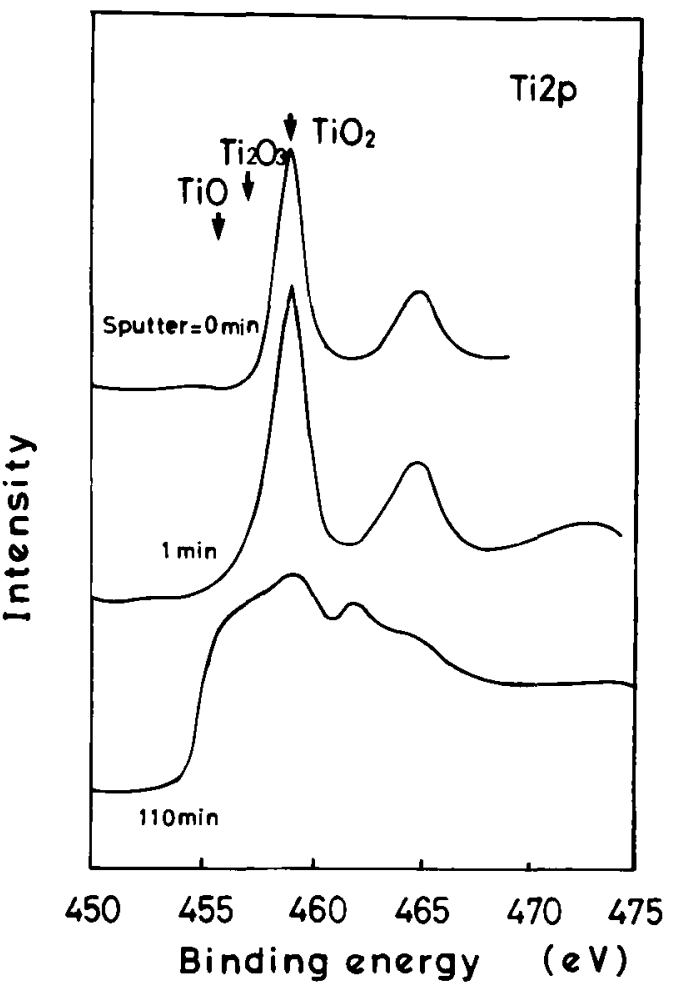

Fig. 3 Change of Ti2p XPS spectra for $\mathrm{TiO}_{2}$ as a function of Arion sputtering time.
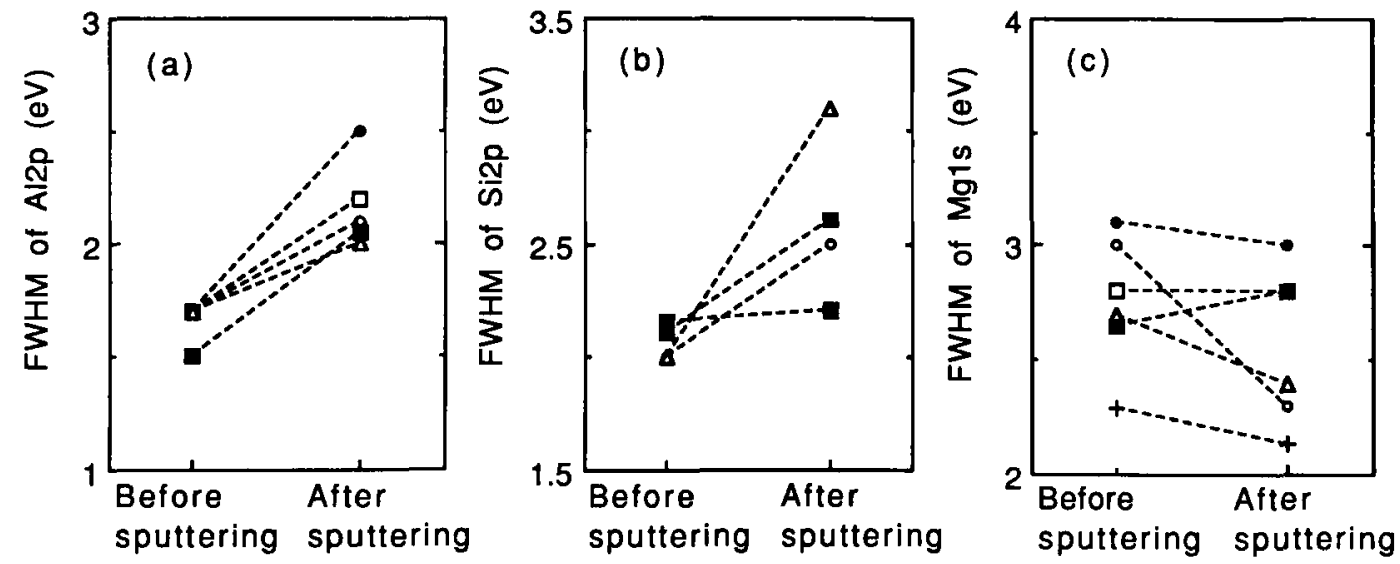

Fig. 4 FWHM of (a) $\mathrm{Al} 2 \mathrm{p}$ line of $\mathrm{Al}_{2} \mathrm{O}_{3}$, (b) $\mathrm{Si} 2 \mathrm{p}$ line of $\mathrm{SiO}_{2}$ and (c) $\mathrm{Mg} 1 \mathrm{~s}$ line of $\mathrm{MgO}$ before and after Ar ion sputtering. (Lab. : ๑; B, O; C, ๑; D, $\Delta ; \mathrm{E}, \mathbf{\square} ; \mathrm{I},+$; K)

The diagram is shown in Fig. 5. We apply the Kelley's criteria for the oxides that are reduced. $\mathrm{Ha}^{\mathrm{i}}$ and $\mathrm{Ha}^{\mathrm{r}}$ are the free formation enthalpy of the starting oxides and reduced oxides, respectively. We used the ionicity (I) that Pauling defined [8] as the parameter of the bond character. The diagram predicts how the chemical state of the oxides can be changed by ion sputtering; the oxides in the region $\mathrm{A}\left(\mathrm{Ha}^{\mathrm{i}}<\mathrm{Ha}^{\mathrm{r}}\right.$ and $\left.\mathrm{I}>0.5\right)$ are unchanged, the oxides in the region $\mathrm{B}\left(\mathrm{Ha}^{\mathrm{T}}<\mathrm{Ha}^{\mathrm{i}}\right.$ and $\left.\mathrm{I}<0.5\right)$ are damaged and the oxides in the region $\mathrm{C}$ $\left(\mathrm{Ha}^{\mathrm{i}}>\mathrm{Ha}^{\mathrm{r}}\right)$ are reduced. 


\section{SUMMARY}

The round robin experiments by the seven laboratories have been performed in order to correct the shift of the binding energy of XPS spectra for $\mathrm{Al}_{2} \mathrm{O}_{3}, \mathrm{SiO}_{2}, \mathrm{MgO}, \mathrm{TiO}_{2}$ and $\mathrm{NiO}$ and to establish the criteria of the change of the chemical state for the oxides by ion sputtering. We have revealed that the O1s XPS line gives a better correction of the binding energy shift by the charge up than the C1s XPS line does. Moreover, a oxide can be unchanged or damaged or reduced by ion sputtering and the change can be predicted by the ionicity and the free formation enthalpy

This work was performed by the surface analysis subcommittee of the Iron and Steel Institute of Japan.

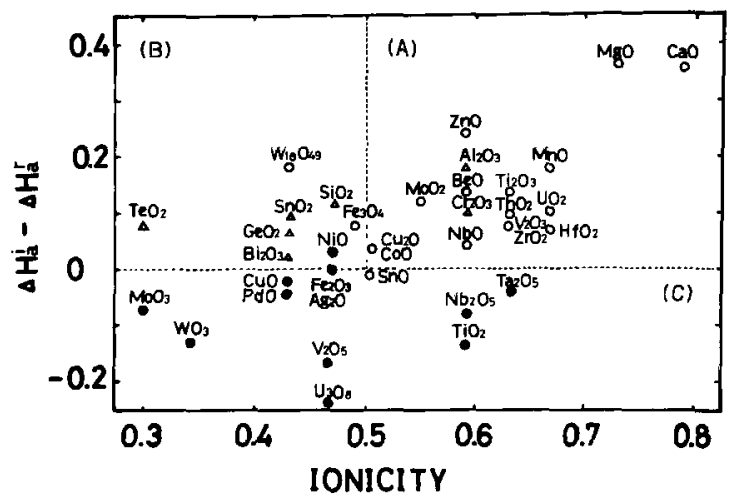

Fig. 5 Surface alteration of various oxides [2] by Ar ion sputtering, which is classified by free formation enthalpy and ionicity defined by Pauling. (region $\mathrm{A}$; unchanged region, $\mathrm{B}$; damage induced region, $C$; reduced region)

\section{REFERENCES}

1. T.Ohstubo, K.Hirokawa, Y.Fukuda, Z.Ohhashi, T.Usuki, N.Gennai, H.Ishida, S.Yoshida, S.Sekimoto and K.Suzuki, Trans. of Iron Steel Inst. of Japan, 27 (1987) 145.

2. H.M.Naguib and R.Kelly, Rad. Eff., 25 (1975) 1.

3. C.D.Wagner, W.M.Riggs, L.E.Davis, J.F.Moulder and G.E.Muilenberg, Handbook of X-ray Photoelectron Spectroscopy, Perkin Elmer, (1979).

4. K.S.Kim and N.Winograd, Surf. Sci., 43 (1974) 625.

5. U.Bardi, K.Tamura, M.Owari and Y.Nihei, Appl. Surf. Sci., 32 (1988) 352.

6. S.Hofmann and J.H.Tomas III, J. Vac. Sci. Technol., B1 (1983) 43.

7. R.Kelly, Surf. Sci., 100 (1980) 85.

8. L.Pauling, The Nature of the Chemical Bond, Cornell university press, 1960. 